\section{THE FIRES OF CHANGE:}

\section{KIRK, POPPER, AND THE HERACLITEAN DEBATE}

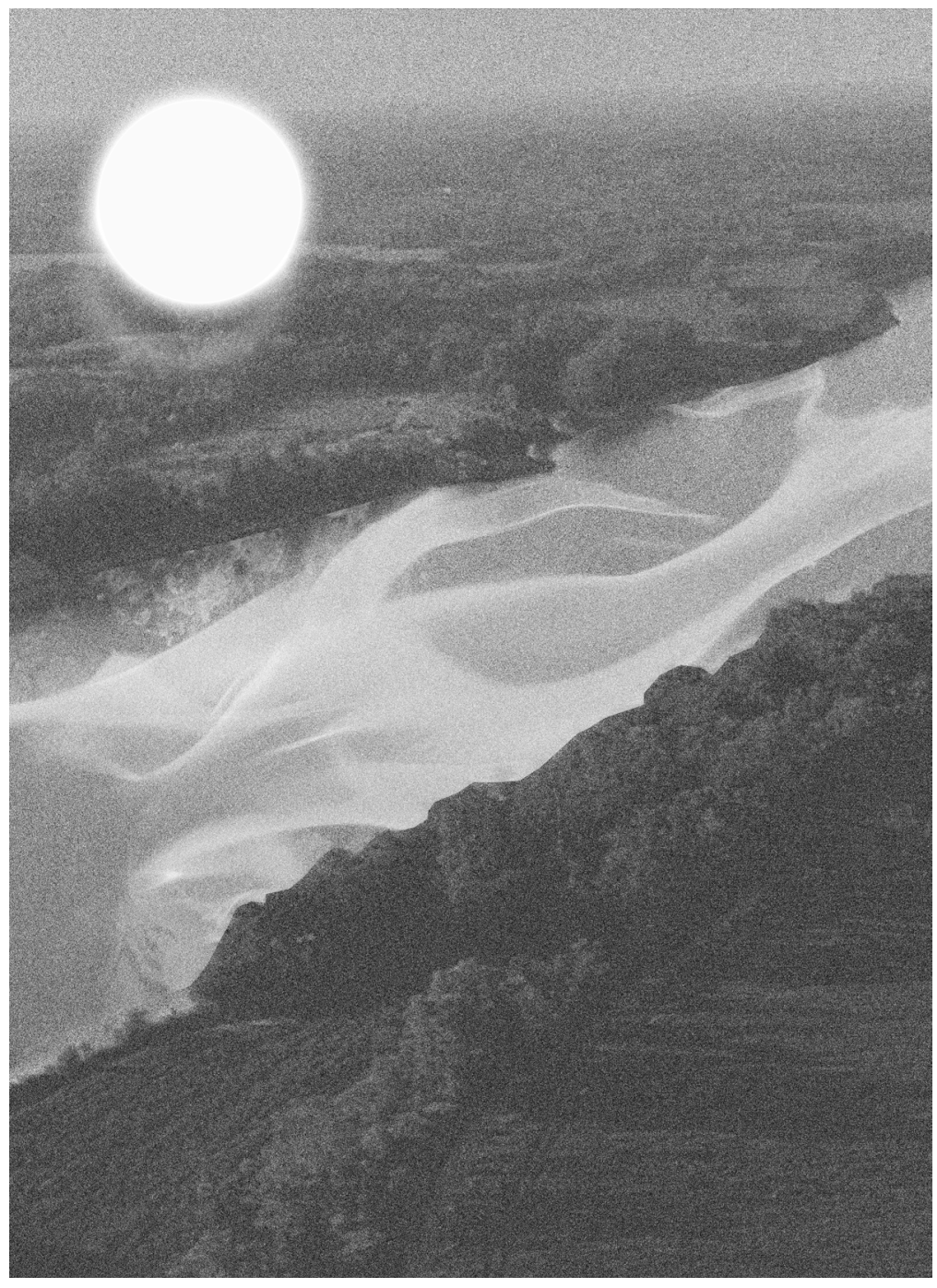

\section{HOLLY COOPER}

\section{ABSTRACT}

In this paper, I explore a prominent question of Hericlitean scholarship: how is change possible? Karl Popper and G. S. Kirk tackle this same question. Kirk asserts that Heraclitus believed that change is present on a macrocosmic level and that all change is regulated by the cosmic principle logos. Popper, on the other hand, claims Heraclitus believed that change is microcosmic and rejected that all change is regulated by logos. I argue for a combination of aspects from each of their claims and conclude that change is present both microcosmically and macrocosmically and that all change is governed by logos.

\section{INTRODUCTION}

A fire was struck between two scholars on October 13, 1958 during a meeting of the Aristotelian Society in London. In his address to the group, Karl Popper - the then-president of the Society and one of the most well-known philosophers of the twentieth centurycriticized Geoffrey Kirk - a scholar of Ancient Greek who was smalltime compared to Popper-for his work on Heraclitus. ${ }^{1}$ This criticism ignited a feud comprised by series of heated essays that the men composed over the next few years. I will primarily be focusing on two of these: Kirk's "Popper on Science and the Presocratics," and Popper's "Kirk on Heraclitus, and on Fire as the Cause of Balance."

The debate, for the most part, can be captured within one central question that Popper outlines concisely: "How is change possible? How can a thing change without losing its identity-in which case it would no longer be that thing which has changed?"3 Popper keeps with the traditional line of thinking and argues that Heraclitus believed that everything is constantly changing: everything is a process rather than a "thing." His thesis, attributed to Heraclitus, is as follows: "there are no (unchanging) things; what appears to us as a thing is a process. In reality a material thing is like a flame; for a flame seems to be a material thing, but it is not: it is a process; it is in flux; matter passes through it; it is like a river." "It is certainly necessary to note that Popper's emphasis is specifically on the micro; when he refers to a "thing," he means an individual object/process. He considers the macro, the whole of the universe, only briefly, and quickly turns away from it again, not

1 Karl R. Popper, "Back to the Pre-Socratics: The Presidential Address," Proceedings of the Aristotelian Society 59 (1958-1959): 1; 15-17; G. S. Kirk and J. E. Raven, The Presocratic Philosophers: A Critical History with a Selection of Texts (London: Cambridge University Press, 1957).

2 G. S. Kirk, "Popper on Science and the Presocratics," Oxford University Press 69, no. 275 (1960): 318-339; Karl R. Popper, "Kirk on Heraclitus, and on Fire as the Cause of Balance," Oxford University Press 72, no. 287 (1963): 386-92.

Popper, "Kirk on Heraclitus," 386.

4 Popper, "Kirk on Heraclitus," 386-87.

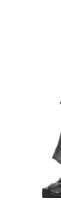


giving any credit to the idea of cosmic change. ${ }^{5}$ Kirk, on the other hand, offers the unorthodox claim, which in reality was already being argued around one hundred-fifty years prior, that Heraclitus posited constant change in the world as a whole, rather than in singular "things." Like Popper, Kirk does not reject the idea running counter to his - that change is present in singularities - but rather gives it far too little credit.

Here, I explore both sides of this debate; however, ultimately, the ideas of both philosophers are correct in their own way, and the combination of certain elements from each of their papers offers a more comprehensive understanding of what Heraclitus actually taught. The correct conjunction of their claims is this: both at the micro-level of singular objects and the macro-level of the universe as a whole, and everywhere in between, everything is in a constant state of change which is governed by the cosmic principle logos.

\section{MOTION IN THE WHOLE AND THE SINGULAR}

The first point to prove is Popper's idea that motion, or change, is present in singular objects. Kirk rejects the permeance of the idea of motion in singularities, suggesting that Heraclitus did not insist that "all things are a process," but that the world of objects is more ordered than Popper asserts. ${ }^{7}$ This claim does not make much sense if one consults the evidence. For instance, Heraclitus accordingly says in F32, "God: day/night, winter/summer, war/peace, fullness/hunger. He changes like fire which, when mixed with spices, is named according to the savour of each." "Regardless of what or who "God" is in this fragment, Heraclitus is clearly not only recognizing but emphasizing the flux between opposites of particular things. It is not entirely clear what he means by "mixed with spices," but it seems to me that the

5 Popper, "Kirk on Heraclitus," 388. I will return to this passage in the next section.

6 Aryeh Finkelberg, "On Cosmogony and Ecpyrosis in Heraclitus," The American Journal of Philology 119, no. 2 (1998): 195; Kirk, "Popper on Science," 337. Kirk's argument regarding Heraclitus is nestled underneath a larger argument concerning Popper's theory of scientific intuition, which I try my best not to be distracted by. Because of this, however, it is more difficult to pinpoint where Kirk's exact thesis regarding Heraclitus lies in his paper-if he even posits an exact thesis at all; for the most part, he is just responding to Popper's criticisms, so I am simply paraphrasing his argument here.

7 Kirk, "Popper on Science," 338.

8 The First Philosophers: The Presocratics and the Sophists, trans. Robin Waterfield (Oxford: Oxford University Press, 2000), 41. All translations of fragments in this essay come from Waterfield. Popper later criticizes claims such as this one that are attributed to Hippolytus's Refutation of All Heresies (Popper, "Kirk on Heraclitus," 390-91.) very fact that Heraclitus ascribes a "savour" to each singularity is enough to prove that the change contained within "things" is an important part of his philosophy. We can further affirm this if we look at F13, in which Heraclitus recognizes more singularities: "living and dead, sleeping and waking, young and old." Again, there are several instances here of singular conditions that are affected by motion and process. For example, the processes of waking up and falling asleep affect the conditions of being awake or asleep. This importation of process onto condition alone is enough to rectify Kirk's disproportionate claim.

We must next look to the several fragments which support Kirk's idea that change is present in the unified whole of the universe, not just the singular. Let us take two examples together: that the universe is "single and common"10 and that "war is common, and strife is justice, and that everything happens in accordance with strife and necessity." 11 It is not difficult to interpret the first example: the universe, in truth, is a unified whole; it is "common." We can see in the second example that war is "common" as well; strife is present in the most general sense of the universe. It is not only the singularities that are governed in accordance with flux, but in fact "everything," which I take to mean every possible combination of things up to the entirety of the universe.

Finally, we must combine these two ideas - that change is present both in the micro and the macro. It is now that we arrive at the pinnacle of Heraclitean imagery: "It is impossible to step twice into the same river...It scatters and regathers, comes together and dissolves, approaches and departs." 12 This image, which is truly more like a motion picture, captures the essence of the correct combination of Kirk and Popper's claims. The pieces of the river-the singularities, the billions of drops of water that make it up-altogether form the whole river, but neither the individual part nor the complete whole is constant. The drops all move and change, but because of this, the river as a macrocosm in its entirety is never exactly the same. Taken this way, the moving image of the river is unable to fully support, in their indignation, either Popper or Kirk's argument.

Popper, on one hand, has an interpretation of the river that differs from the one given above. He claims that "the rivers are concrete rivers," which symbolize concrete singularities, including people. ${ }^{13}$ This is indeed strange: Popper is giving microcosmic qualities to the river. He even imposes plurality onto the rivers; there are several of them, so therefore the river, to him, cannot represent a unified whole. But this seems counter-intuitive for his argument. How can singular things be

9 The First Philosophers, 39.

10 The First Philosophers, 38

11 The First Philosophers, 40

12 The First Philosophers, 41.

13 Popper, "Kirk on Heraclitus," 388. 
in motion if the river symbolically ascribes concreteness to them? How can Popper make a claim so absurd as to say that humans and rivers are concrete? It seems that if Popper really meant to preserve the fluidity of singularities, then he would have picked a word better than "concrete," so what meaning can he really expect us to see here? I hold this against him: the image of a "concrete river" is truly oxymoronic.

Kirk, on the other hand, briefly implies a different interpretation: that the river as a whole remains the same river while only its parts change. ${ }^{14}$ Both men favor the phrase "same river" but in two different senses: Popper, because the rivers are "concrete," and Kirk, because he means to highlight not the concreteness of the river but the opposite.

To Kirk, the river is in motion, but there is some other form of stability aside from concreteness that pervades it.

\section{MEASURE, LAW, AND LOGOS}

This other form of stability is the subject of our next discussion. In things both singular and general, there is some aspect of the constancy of motion, not just the presence of it. That constancy, though, does not arise from things in virtue of themselves. Instead, it arises from what Waterfield translates as "the principle" in the Heraclitean fragments. It is logos - the ultimate voice of cosmic law and measurement. This is the subject in which Kirk is right and Popper is partly wrong.

Kirk attributes to Heraclitus the belief that all things, although in motion, maintain an equilibrium which is guaranteed by logos. Change is present both singularly and universally, but logos naturally regulates this change in order to preserve general stability. ${ }^{15}$ Popper rejects this: while he does say that things appear stable, so the processes behind them must be measured and lawlike, he vehemently denies that all changes are stable and that logos is common between all things. Essentially, he rejects that Heraclitus believed any of the following: (a) that all changes are regulated as opposed to only certain ones; $(b)$ that fire is the cause of regulation; and $(c)$ that fire is synonymous with logos. ${ }^{16}$ Popper claims that he is completely unable to find even a trace of the doctrines that he rejects in the fragments or any other ancient sources. ${ }^{17}$ Quite frankly, he has not looked hard enough. These elements that Popper deems "absurd" are all important components of Kirk's correct argument that, according to Heraclitus, constancy in motion is a characteristic of all things and that this is made possible by overarching logos.

14 Kirk, "Popper on Science," 338.

15 Kirk, "Popper on Science," 338.

16 Popper, "Kirk on Heraclitus," 390.

17 Popper, "Kirk on Heraclitus," 390.
I would like to begin with a consideration of $(c)$ - that fire is synonymous with logos. Heraclitus outlines in one fragment the "turning-points of fire." Fire turns to sea (which is half earth and half lightning), and then sea returns to "the same principle [logos] as before it became earth." 18 The starting point here is fire, so if sea must return to the starting point of the cycle before it became earth, and what it is returning to is $\log o s$, then Heraclitus must equate fire with logos. From this, we have proven $(c)$ to be true.

We must next prove (a), that all changes are regulated as opposed to only certain ones. It will be easiest to do this by first providing evidence for balance in microcosms and then providing evidence for balance in macrocosms.

According to one fragment, "[t]he sun, according to Heraclitus, is new each day." ${ }_{19}$ Heraclitus also says, "The sun will not overstep its measures." ${ }^{20}$ Even Popper admits, correctly, that it can be seen from the first fragment that Heraclitus regarded the sun as a singularity. ${ }^{21}$ From the second, we see that the sun - a singularity, a microcosmmust necessarily stay within the bounds of measure, proving that microcosmic motion, according to Heraclitus, is regulated.

So now we turn to the macro. Heraclitus says that "the principle [logos] is common." ${ }^{22}$ We saw earlier that Heraclitus believed the universe to be a unified whole - to be common — and now we are seeing that $\operatorname{logos}$, too, is common. The connection between logos and universal oneness is undeniable, especially if we supplement this fragment with another: "[i]t is also law to follow the plan of the one." 23 The "law" can be taken to be logos, while the "one" can be taken to be the macrocosmic universe. Logos pervades throughout the whole of existence.

Finally, I turn to $(b)$, that fire is the cause of regulation. Heraclitus claims that order cannot be attributed to any god or man, but that it instead "always was and is and shall be an ever-living fire, flaring up in regular measures and dying down in regular measures." ${ }^{24}$ Clearly, measure and regularity here are attributed to fire, which, as we have seen, is equated with logos. This fragment is enough evidence to prove that Heraclitus believed $(b)$ - that fire/logos is the cause of universal equilibrium.

It is unclear why Heraclitus held the beliefs that he did regarding motion and regulation, as we have seen. Due to the fragmentary nature

8 The First Philosophers, 42

19 The First Philosophers, 43

19 The First Philosophers, 43.

20 The First Philosophers, 43.

21 Popper, "Kirk on Heraclitus," 387-88.

22 The First Philosophers, 38.

23 The First Philosophers, 45.

24 The First Philosophers, 41-42. 
of the Heraclitean works that the philosophical world has access to, it is easy to speculate about what Heraclitus meant, especially regarding the logos that we have just discussed. Several unanswered questions still remain about this subject, even after hundreds of years of scholarship.

For example, why would Heraclitus believe fire to be logos when water seems to work just as well for his purposes, especially since his image of the river seems to serve basically the same purpose as any image of fire that he sets forth? Through what physical or metaphysical means did Heraclitus believe his conception of logos to regulate the universe? And in regard to the two philosophers that we have been focusing on, why would Popper choose to attack Kirk over ideas that seem to be obviously present in the Heraclitean fragments? When one attempts to answer these questions, the fragments must be carefully examined, and the examiner must fit them together like pieces of a puzzle. However, as we now know, it is easy for philosophers to force puzzle pieces into place when answering these questions instead of thoughtfully placing them.

\section{CONCLUSION}

These questions are important, but the fundamental question remains the same: "How is change possible?" We have seen that both Popper and Kirk's responses to this are correct in some ways and defective in others. The attitudes of both men in their papers are seething; they are riddled with indignation. It may be for this reason that they seem, at times, to posit claims that are not fully coherent with their general arguments and even sometimes go as far as contradicting themselves. They have fallen victim to the very thing Socrates warned against when he said to Gorgias, "So I'm afraid to refute you, lest you suppose that I speak from love of victory, not in regard to the subject's becoming manifest, but in regard to you." ${ }^{25}$ If only these two men had been able to put aside petty differences, they might have been able to engage in a dialogue that would have done the philosophical community a world of good by pushing us ever closer to the true understanding of what Heraclitus did, in fact, believe. Instead, they only divided the two schools of thought even more. However, as we have seen, Popper is correct on microcosms, Kirk is correct on macrocosms, and only Kirk is correct regarding motion. By expanding on elements from Popper's highly traditional view and Kirk's largely controversial view, a conception of Hericlitean thought has been formulated that I believe is more accurate than either of theirs taken individually - that both the macro and the micro are everchanging, but that this motion is kept in check by the universal governing principle logos.

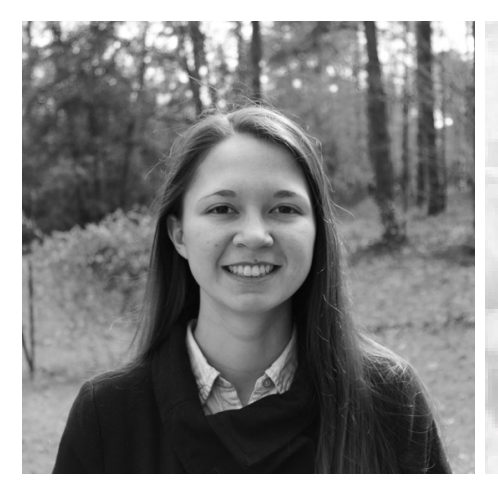

ABOUT THE AUTHOR: Holly Cooper attends Mercer University in Macon, Georgia, where she is in her third year as a philosophy major and an English minor. Her primary philosophical interests are in phenomenology, epistemology, ancient Greek philosophy, and practical ethics. She also enjoys playing and teaching drums. 